\title{
Development of Mission and Vision of College of Korean Medicine Using the Delphi Techniques and Big-Data Analysis
}

\author{
Sanghee $\mathrm{Yeo}^{1}$, Seong Hun $\mathrm{Choi}^{2}$, Su Jin $\mathrm{Chae}^{3 *}$ \\ ${ }^{1}$ Department of Medical Education, School of Medicine, Kyungpook National University \\ ${ }^{2}$ Department of Anatomy and Histology, College of Oriental Medicine, Daeggu Haany University \\ ${ }^{3}$ Department of Medical Education, Catholic Kwandong University College of Medicine
}

\begin{abstract}
Objectives: The purpose of this study is to introduce the procedures and methods for mission and vision development at a College of Korean Medicine (CKM), which established its mission and vision using Delphi techniques and big data analysis on various members and stakeholders.

Methods: A total of 754 participated in the Delphi survey. A Delphi survey was conducted with professors, students, parents, and alumni stakeholders to establish Daegu Haany University CKM's mission and vision. The data were analyzed through content analysis and big data analysis of keywords.

Results: As a result of the study, the most important keywords to be included in the mission and vision were "professionalism" and "morality." Included in the mission were the concepts of "morality" and "professionalism," which were emphasized by the four groups. All surveyed stakeholders regarded "scientific," and "global" as important themes to be included in the vision.

Conclusions: The present study confirmed that there were themes commonly prioritized by all stakeholders for college mission and vision, and a difference in demand for educational goals between professors and students was also affirmed. Therefore, institutions of higher learning should develop their mission and vision by appropriately reflecting the needs of the interest groups.
\end{abstract}

$\overline{K e y}$ Words : Mission, Delphi Technique, Stakeholder, Republic of Korea, Korean medicine education

\section{Introduction}

Mission and vision are concepts primarily used as strategic management tools in business administration[1,2]. Universities are more familiar with terms such as 'educational ideal' or 'education goal' than terms such as mission or vision. Mission is defined as the reason for the existence of an institution, that is, its value of existence; vision refers to a blueprint that specifically shows the direction toward which the institution aims [3]. Applying these definitions to university institutions, mission can be thought of as "the reason for the existence of the university" and vision as "the specific roles and goals that express what the university wants to achieve." When considering the higher education, research, and service responsibilities, its mission and vision

\footnotetext{
- Received : 12 October 2021

- Revised : 1 November 2021

- Accepted : 5 November 2021

- Correspondence to : Su Jin Chae

Department of Medical Education, Catholic Kwandong University College of Medicine, Incheon, Korea

Tel : +82-32-290-2972, E-mail : edujin@cku.ac.kr
} 
are not limited to educational sector. An image of the university that society wants has long existed. In addition to education, universities have the role of the social accountability, including answering to the demands of the times, creating knowledge that responds to the future of society, passing on contemporary knowledge and wisdom to the next generation, and making social contributions to the community and country to which the university belongs [4]. Therefore, a university's mission and vision determine the direction toward which the university should aim, which can serve as a standard of judgment for the university's operation, such as student admission and curriculum development.

Recently, as Colleges of Korean Medicine in Korea are preparing the new accreditation standards by Institute of Korean Medicine Education and Evaluation (IKMEE) [6], which comply with the global standards for basic medical education (BME) of the World Federation for Medical Education (WFME), it is becoming increasingly important to establish a mission and vision. This accreditation stipulate as a basic standard that a "College of Korean Medicine (CKM) must develop a mission and inform college's members and health officials of it." According to the "Mission and Performance" of new accreditation standards by IKMEE [6], each CKM must clarify its reason for existence as well as its aims and clearly describe the requirements of the college's members. CKMs have the social responsibility to respond to health needs and challenges of the state and local communities, readjust their priorities in education, service, and research, and cooperate with their members and health care officials. According to the WFME [5], social responsibility includes responding to the demands of society, patients, healthcare, and healthcare -related fields as well as the will and ability to contribute to the development of national and global medicine by strengthening competitiveness in medical services, medical education, and research.

Member consensus is important when establishing a mission or vision. Therefore, it is essential for CKMs to form a consensus among their members as to why they need to establish a mission and vision. CKMs must create committees to do such work and fully inform college's members to form a consensus through public hearings and meetings. Studies on establishing missions and visions have been conducted at both for-profit and non-profit institutions, such as hospitals and libraries [7, 8], but the development procedure and method have not been introduced in detail. Not only in the CKM, but also in the fields of health care such as medicine, nursing, dentistry and pharmacy, there is a lack of research on the college's mission and vision development $[9,10]$.

This study aims to introduce the procedures and methods for mission and vision development at one College of Korean Medicine, which established its mission and vision using Delphi techniques and big data analysis on various stakeholders including professors, students, parents, and alumni. It is hoped that this study serves as basic material for CKMs to utilize in developing missions and visions.

\section{Discussion}




\section{Participants}

The participants giving opinions on the mission and vision included 655 enrolled students and 66 employed professors from Daegu Haany University CKM in 2020 and 47 parents. Thus, a total of 820 people participated in the Delphi survey. Of these, 754 responses were used as data, excluding those from participants who did not consent to the survey and those with incomplete answers.

The survey showed a $92 \%$ response rate from 25 professors of CKM (37.8\%), 655 enrolled students (100\%), 28 parents (59.6\%), and 46 alumni $(88.5 \%)$.

\section{Delphi technique}

This study expanded the scope of an expert group and modified the existing Delphi technique to the study. The Delphi technique was developed in the 1950s by the Rand Corporation in the United States and is an expert-opinion survey method that can prevent adverse effects during face-to-face discussions [11]. The method has the advantage of collecting multiple opinions through repetitive opinion collection and controlled feedback and allows for an easy way to conduct and present opinions regarding the future [12]. The Delphi technique was judged to be appropriate for this study as it had to collect opinions while mediating differences among stakeholders to develop a mission and vision. The study expanded the scope of experts and collected opinions from all stakeholders including professors, students, parents, alumni, and the study included three stages of large-scale opinion collection processes. While the existing Delphi technique induced collective agreement by repeatedly examining the opinions of 5-20 experts who were already asked about the problem 2-3 times, this study tried to expand the expert group to listen to the various opinions of educational members such as professors, students, parents, and alumni. In the modified Delphi method, for the first round, answers were taken from a survey done via email among professors, alumni, and students to identify various opinions. In the subsequent round, 10 experts analyzed and ranked the opinions from the first round. This method has the advantage of inducing agreement among various group members without investigating opinions from the same experts repeatedly.

The Delphi questionnaire used in the study has 41 questions consisting of 23 open-ended questions and 18 multiple-choice questions rated on a five-point Likert scale. The open-ended questions asked participants to state what should be included in Daegu Haany University CKM's mission and vision in preparation for the society of the future.

The questionnaire was reviewed by a professor at the medical school, two professors at the medical school specializing in pedagogy, one practicing Korean medicine doctor, and one professor at the CKM to ensure content validity. The survey was conducted from December 10 to 30, 2020, using Google online platform.

\section{Data Analysis}

First, the Word Cloud method, a big data analysis method, was used for data analysis. Word Cloud is an analysis technique that visualizes the number of keywords based on frequency analysis [13]. The method is the 
simplest and most commonly used method for analyzing texts and allows for quick identification of the core content. Second, with regard to the content to be included in the mission and vision of CKM in preparation for the society of the future, keyword frequency was derived through keyword content analysis, and the frequency was compared among respondents. Keywords for mission and vision were analyzed up to the top 50 , and comparisons among respondents were made up to the top 20. The top 50 and top 20 were specifically chosen because this allowed for a significant distinction. If set wider than this, too many keywords with the frequency of one would be returned, and the comparison would not be significant.

\section{Development Procedures}

The mission and vision development process specifically followed the procedures outlined in Table 1. The process can be divided into four parts. First, a Committee was set up to form a group of experts, and research was conducted by forming a research team of educators, Korean medicine doctors, and western medicine scholars. Second, a Delphi questionnaire was created based on a literature survey on mission and vision to collect opinions from stakeholders. Third, the questionnaire underwent three rounds of surveys and an opinion collection process. Fourth, the final draft went through an administrative procedure in accordance with university regulations.

Table 1. Mission and Vision Development Process

\begin{tabular}{|c|c|}
\hline Procedure & Contents \\
\hline $\begin{array}{l}\text { Formation of the committee and } \\
\text { research team }\end{array}$ & $\begin{array}{l}\text { Formation of the committee consisting of professors, alumni associations, Daegu City officials, } \\
\text { and parent association representatives } \\
\text { The research team consisted of educators, Korean medicine doctors, and western medicine } \\
\text { scholars. }\end{array}$ \\
\hline Literature review & $\begin{array}{l}\text { 1. Survey on mission and vision of each school } \\
\text { 2. Preparation of assessment questionnaire (draft) }\end{array}$ \\
\hline Questionnaire preparation & $\begin{array}{l}\text { Questionnaire preparation } \\
\text { - Review by chairperson of department } \\
\text { - First draft reviewed and revised by research team } \\
\text { - Questionnaire draft decided } \\
\text { - Survey questions created online }\end{array}$ \\
\hline Implementation of the survey & First online survey \\
\hline Survey analysis & Opinion analysis on mission and vision \\
\hline $\begin{array}{l}\text { Preparation of mission and vision } \\
\text { Submission to professors' general } \\
\text { meeting }\end{array}$ & $\begin{array}{l}\text { 1. Submission of mission and vision (draft) to professors' general meeting } \\
\text { 2. Opinions collected at professors' general meeting }\end{array}$ \\
\hline $\begin{array}{l}\text { Second round of opinion collection } \\
\text { and revision for mission and vision }\end{array}$ & Second opinion collection from professors, alumni, and students (online survey) \\
\hline $\begin{array}{l}\text { Third round of opinion collection } \\
\text { and revision for mission and vision }\end{array}$ & Third revision and supplementation by research team \\
\hline Finalization of draft & $\begin{array}{l}\text { 1. Review by scholars of Korean language } \\
\text { 2. Committee and the group of deans finalize the draft }\end{array}$ \\
\hline Submission of final draft & The committee submits the final draft to the group of deans through official document \\
\hline
\end{tabular}



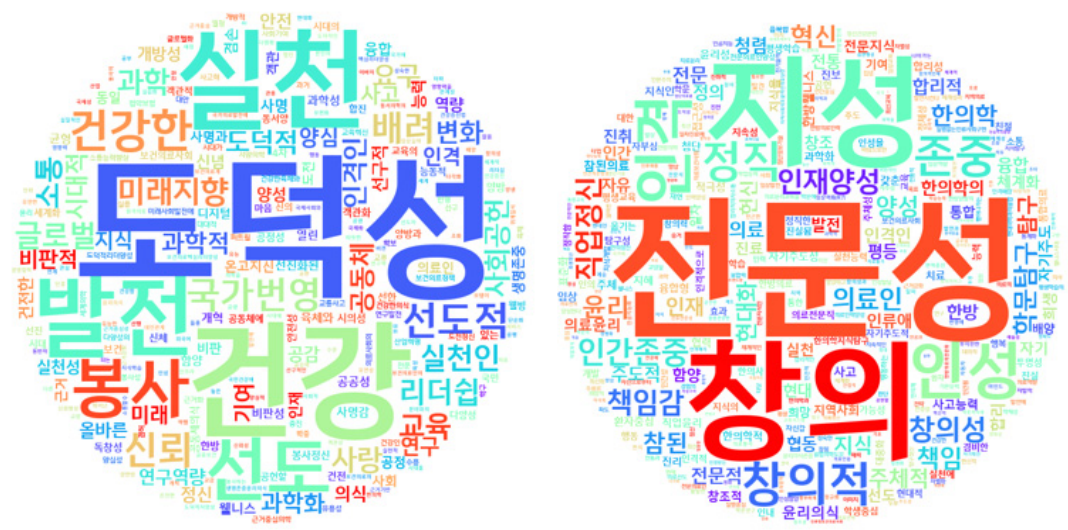

Fig. 1. Results of word cloud analysis on mission and vision keywords

\section{Ethical considerations}

In the Delphi survey of opinions for establishing its mission and vision, only the data of professors, students, parents, and alumni who were fully informed of the purpose of the survey and who provided consent in writing were used for analysis. The survey was conducted anonymously, and the data processing was given IDs so that individuals could not be distinguish from others.

\section{Discussion}

\section{Content analysis of keywords to be included in the mission and vision}

There were 2,507 responses for content to be included in the mission and 2,494 responses for content to be included in the vision in preparation for the society of the future. Figure 1 shows the analysis results of the keywords using Word Cloud. For mission, regarding the analysis results of the keywords from 5,001 responses, the top three were as follows: "morality" was mentioned 143 times, "practitioner" was mentioned 136 times, and "health" were mentioned 70 times. For vision, "professionalism" were mentioned the most at 135 times, "creativity" were mentioned 84 times, and "intelligence" were mentioned 69 times.

\section{Stakeholders' opinions over mission keywords}

A comparison of the stakeholders of professors, students, parents, and alumni with regard to important content to be included in the mission showed that all four stakeholders chose "professionalism", "morality", and "human respect" as important keywords. In the four stakeholders, "professionalism" was ranked third, "morality" fifth, and "health" tenth in terms of importance. "human respect" was ranked within the top five for community leaders, professors, and parents but lower than the top ten for students. "Service" ranked in the top ten for professors, students, and parents but was not mentioned within the top 20 for community leaders (Table 2). 


\section{Stakeholders' opinions over vision keywords}

In a comparison among professors, students, parents, and alumni with regard to important content to be included in the vision, all groups ranked "scientific", and "global" as important. "Morality" ranked in the top three for professors, students, and parents. "Health", "professionalism", and "progress" ranked in the top 20 for professors and students, while "communication" ranked in the top 20 for all stakeholders except for parents (Table 3).

\section{Discussion and Conclusions}

This study aimed to introduce the procedures and methods for mission and vision development at a CKM. Using the Delphi and big data methods, it examined the keywords that various stakeholders consider important, analyzed the differences in opinions among the groups, and established a mission and vision for CKM that members agreed on.

Keywords were derived from a literature review on missions and visions and from 754 participants, including professors, students, parents, and alumni, the mission and vision of the CKM were established by comparing the stakeholders. Once the priority of keywords was determined using the Delphi survey, the differences in

Table 2. Resulting stakeholders' opinions on mission keywords

\begin{tabular}{|c|c|c|c|c|c|c|c|c|}
\hline Rank & Alumni & Frequency & Professors & Frequency & Students & Frequency & Parents & Frequency \\
\hline 1 & Creativity $^{\mathrm{a}}$ & 10 & Professionalism $^{b}$ & 4 & Professionalism $^{\mathrm{b}}$ & 96 & Human respect $^{\mathrm{d}}$ & 4 \\
\hline 2 & Professionalism & 8 & Morality $^{c}$ & 3 & Morals $^{\mathrm{c}}$ & 85 & Social service & 4 \\
\hline 3 & Practice & 5 & Human respect $^{\mathrm{d}}$ & 2 & Creativity $^{\mathrm{a}}$ & 69 & Morality c & 3 \\
\hline 4 & Morals $^{c}$ & 4 & Philanthropy & 2 & Health & 59 & Development & 3 \\
\hline 5 & Human respect $^{\mathrm{d}}$ & 4 & Creativitya & 2 & Practice & 53 & Love & 3 \\
\hline 6 & Character & 4 & Health & 1 & Intellect & 50 & Trust & 3 \\
\hline 7 & Professional & 4 & Scientification & 1 & Personality & 44 & Character & 3 \\
\hline 8 & Health & 4 & Tolerance & 1 & Character & 41 & Professionalism ${ }^{\mathrm{b}}$ & 3 \\
\hline 9 & Science & 3 & Public health & 1 & Development & 35 & Creative $^{\mathrm{a}}$ & 3 \\
\hline 10 & Personality & 3 & Internationalization & 1 & Service & 33 & Health & 2 \\
\hline 11 & Integrity & 3 & Diversity & 1 & Leadership & 32 & Research & 2 \\
\hline 12 & Intellect & 3 & Volunteerism & 1 & Integrity & 31 & Respect for life & 2 \\
\hline 13 & Education & 2 & Social service & 1 & Talent training & 24 & Knowledge & 2 \\
\hline 14 & Love & 2 & World consciousness & 1 & Respect & 23 & Wisdom & 2 \\
\hline 15 & Ethics & 2 & Communication & 1 & Work ethic & 22 & Responsibility & 2 \\
\hline 16 & Respect for life & 2 & Ethical & 1 & Responsibility & 21 & Sense of mission & 1 \\
\hline 17 & Korean medicine & 2 & Convergence & 1 & National prosperity & 20 & Thinking & 1 \\
\hline 18 & Wellness & 1 & Medical ethics & 1 & Human respect & 20 & Healthy life & 1 \\
\hline 19 & Sympathy & 1 & Contribution to community & 1 & Creativity & 19 & Sympathy & 1 \\
\hline 20 & Social contribution & 1 & Standardization & 1 & Academic exploration & 19 & Healthy community & 1 \\
\hline \multicolumn{2}{|c|}{ Number of keywords } & 137 & & 42 & & 2,236 & & 92 \\
\hline \multicolumn{9}{|c|}{ Total number of keywords: 2,507 } \\
\hline
\end{tabular}


opinions among the members were analyzed, and the content that achieved the highest consensus was determined as the mission and vision. A total of 5,001 responses were obtained from the keyword survey to be included in the mission and vision. Significant keywords included "professionalism", "morality", and "practitioner" for the mission and "creativity", "morality", and "scientific" for the vision. "Morality" was the most important for the mission, and "globalization" and "global" were the most important for the vision. An analysis of the differences in opinions for the mission and vision showed that local medical officials highly valued "respect for humans", and students and professors considered "service" important. This reflects the changing demands of Korean medicine and is a meaningful result showing regional characteristics and opinions between stakeholders. Therefore, CKM should develop missions and visions by appropriately reflecting the needs of interest groups, and to achieve this in the future, they must develop curricula and teaching methods accordingly.

The mission and vision of CKMs must specify the basic level of medical competency, the basic conditions necessary for various Korean medical activities, and the role of Korean medicine doctors as suggested in the Korean medical competency model [14]. Furthermore, they should

Table 3. Resulting stakeholders' opinions on vision keywords

\begin{tabular}{|c|c|c|c|c|c|c|c|c|}
\hline Rank & Alumni & Frequency & Professors & Frequency & Students & Frequency & Parents & Frequency \\
\hline 1 & Creative intellectual & 9 & Health & 3 & Creative talent & 117 & Global $^{b}$ & 5 \\
\hline 2 & Scientific $^{\mathrm{a}}$ & 4 & Scientific $^{a}$ & 2 & Professionalism & 93 & Morals ${ }^{\mathrm{c}}$ & 3 \\
\hline 3 & Leadership & 4 & Morality $^{\mathrm{c}}$ & 2 & Morality ${ }^{\mathrm{c}}$ & 73 & Leadership & 3 \\
\hline 4 & Innovation & 4 & Global $^{\mathrm{b}}$ & 2 & Practical & 59 & Innovation & 3 \\
\hline 5 & Future-oriented & 3 & Professionalism & 2 & Health & 54 & Character & 2 \\
\hline 6 & Practice & 3 & Creativity & 2 & Development & 47 & Intellect & 2 \\
\hline 7 & Professionalism & 3 & Justification & 1 & Leading & 46 & Knowledge & 2 \\
\hline 8 & Respect & 3 & Competence & 1 & Global $^{\mathrm{b}}$ & 41 & Work ethic & 2 \\
\hline 9 & Sympathy & 2 & Development & 1 & Intellect & 37 & Globalization & 2 \\
\hline 10 & Development & 2 & Volunteerism & 1 & Creative inquiry & 35 & Service & 2 \\
\hline 11 & Communication & 2 & Communication & 1 & Scientific $^{b}$ & 32 & Health & 1 \\
\hline 12 & Respect for humans & 2 & Practice & 1 & Work ethics & 31 & Science $^{b}$ & 1 \\
\hline 13 & Global $^{\mathrm{b}}$ & 2 & Feasability & 1 & Critical thinking & 30 & Advancement of education & 1 \\
\hline 14 & Morals $^{\mathrm{c}}$ & 2 & Capabilities & 1 & Convergence & 29 & Popularization & 1 \\
\hline 15 & Community & 1 & Research & 1 & Leadership & 29 & Morality & 1 \\
\hline 16 & Giving & 1 & Research & 1 & Personality & 27 & Leadership & 1 \\
\hline 17 & Critical thinking & 1 & Excellence & 1 & Globalization & 23 & Future & 1 \\
\hline 18 & Love & 1 & Well-being & 1 & Regional development & 22 & Philanthropy & 1 \\
\hline 19 & Cooperation & 1 & Ethical consciousness & 1 & Communication & 22 & Respect & 1 \\
\hline 20 & Latest technology & 1 & Convergence & 1 & Innovation & 18 & Professionalism & 1 \\
\hline & Number of keywords & 135 & & 41 & & 2,230 & & 88 \\
\hline
\end{tabular}

Total number of keywords: 2,494 
be able to contribute to the development of national and global medicine by responding to the demands of society, patients, healthcare, and healthcare-related fields and by strengthening the competitiveness of medical services, Korean medical education, and medical research [4].

To develop a mission and vision, this study used the Delphi technique as a method for collecting opinions from various interests and identifying demands. This technique was also used in a study for the development of missions and visions at medical schools $[15,16]$ and is designed for developing the mission and vision of a university. In addition, this study is significant because it involves the first CKM to present its mission and vision development procedure. CKMs that want to develop a mission and vision in the future will be able to do so through appropriate consensus and administrative procedures among stakeholders if they utilize the procedures and methods used in this study.

Korean medical and graduate schools will begin new accreditation in 2022. These colleges will develop their missions as required by the accreditation in various forms and through various methods. This study is meaningful as it provides basic reference material not only for CKMs but also for many universities preparing for developing their mission and vision.

Despite this significance, this research though is subject to several limitations. First, it is difficult to generalize the contents of the present study to other CKMs because the missions and visions pursued by each university are different. Second, there is the likelihood that some participants may have responded without a sufficient understanding of the mission and vision. Therefore, procedures are needed to inform them of the results and review their appropriateness. Given that the survey responses indicate different interpretations of a concept and conflicting demands of a mission, universities should reflect the needs of their members but establish their mission and vision based on their educational philosophy.

Establishing a mission and vision inevitably entails changes in the curriculum and the teaching methods, teaching development, and educational facilities. It is hoped that follow-up studies on the development of curriculums reflecting the mission and vision will continue in Korean medical education.

\section{References}

1. Lee, B. C. (2016). An empirical Study on the effect of the vision establishment on business of SMEs and the consultation methodology on the vision establishment for SMEs [dissertation]. Seoul, Korea: Graduate School of Knowledge Service Consulting Hansung University.

2. Kim, D. J., \& Na, W. H. (2007). A study on the management performance evaluations of vocational rehabilitation facilities for the person with disabilities. Journal of Vocational Rehabilitation, 17(2), 99-120.

3. Kim, S. J. (2015). The effect of a social service organization's mission on the organizational commitment [dissertation]. Jeonju, Korea: Jeonju University.

4. Jung, H., Jeon, W. T., \& An, S. (2020). Is 
accreditation in medical education in Korea an opportunity or a burden? Korean Medical Education Review, 22(1), 16-27. https://doi.org/ 10.17496/kmer.2020.22.1.16

5. WFME. (2021). WFME Global Standards for Quality Improvement: Basic Medical Education. [cited 202108 19].

6. Institute of Korean Medicine Education and Evaluation. (2019). Korean Medicine Education accreditation standards 2021. IKMEE.

7. Kwack, D. C. (2003). A study on the formulation of missions and visions in libraries. Journal of the Korean Library and Information Science, 37, 269-289.

8. Dang, J. Y., Choy, Y. S., \& Kim, Y. H. (2013). A study of mission statements for strategic management: Focusing on the tertiary care hospitals in Korea and special functioning hospitals in Japan. Korean Journal of Hospital Management, 18(1), 70-87.

9. Park, H. J., Lee, H. A., Kim, J. Y., Baek, W. K., \& Lee, S. Y. (2019). The development of mission and vision using Delphi method in a medical school. Keimyung Medical Journal, 38(1,2), 11-16.

10. Kim, Y. J., \& Choi, H. S. (2021). Beginning of outcome-based medical education: Development of medical schools' mission statements based on stakeholders' priority. Korean Journal of Medical Education, 3(3), 215-226.

11. Row, G., \& Wright, G. (1999). The Delphi technique as a forecasting tool: Issues and analysis. International Journal of Forecasting,
15(4), 353-375.

12. Jon, L. (2006). Current validity of the Delphi method in social sciences. Technological Forecasting and Social Change, 73(5), 467-482.

13. Kim, N. G., Lee, D. H., Choi, H. C., \& Wong, W. X. (2017). Investigations on techniques and applications of text analytics. The Journal of Korean Institute of Communications and Information Sciences, 42(2), 471-492.

14. Lim, C., Han, H., Hong, J., \& Kang, Y. (2016). Competency modeling for doctor of Korean Medicine \& application plans. Journal of Korean Medicine, 37(1), 101-113. https://doi.org/10.13048/jkm.16010

15. Park, J. H., Lee, R., \& Sohn, I. S. (2011). Setting school-level educational goal and objectives with the modified Delphi method. Korean Journal of Medical Education, 23(4), 243-252.

16. Olds, G. R., \& Barton, K. A. (2015). Building medical schools around social missions: The case of the University of California, Riverside. Health Systems \& Reform, 1(3), 200-206.

\section{ORCID}

Sanghee Yeo http://orcid.org/0000-0002-6210-6789

Seong Hun Choi https://orcid.org/0000-0002-5942-1550

Su Jin Chae http://orcid.org/0000-0003-3060-8933 